\title{
The "Problem of Extension" revisited: new modes of digital participation in science
}

\section{Sascha Dickel and Martina Franzen}

\begin{abstract}
Citizen Science is part of a broader reconfiguration of the relationship between science and the public in the digital age: Knowledge production and the reception of scientific knowledge are becoming increasingly socially inclusive. We argue that the digital revolution brings the "problem of extension" - identified by Collins and Evans in the context of science and technology governance - now closer to the core of scientific practice. In order to grasp the implications of the inclusion of non-experts in science, the aim of this contribution is to define a role-set of non-certified knowledge production and reception, serving as a heuristic instrument for empirical clarifications.
\end{abstract}

\section{Keywords}

\section{Exclusion and inclusion in science $^{1}$}

Science established itself in modern society as an exclusive system for knowledge production, which offered lay people and amateur scientists hardly any inclusion options $^{2}$ [Schimank, 2012]. In the world of science, scientists have a dual role, namely the production and the reception of knowledge. Since the establishment of the above-mentioned role, all the other members of society have been largely excluded from the production of scientific knowledge. [Ben-David, 1991; Burzan et al., 2008]. Science established itself as a closed social system, separated from the rest of the society by means of knowledge certification practices [Collins and Evans, 2002; Weingart, 2001, pp. 68-84].

In the process of the multi-faceted problematization of scientific expertise, the exclusiveness of scientific knowledge production is being increasingly questioned. At the same time, a more active participation of lay people - at least in a number of research contexts ${ }^{3}$ - is considered a systemically relevant prerequisite for the

\footnotetext{
${ }^{1}$ Our argument is based on considerations developed in Dickel and Franzen [2015] where we tackled the issue of Citizen Science under different theoretical premises, namely the theory of functional differentiation formulated by Niklas Luhmann. The present article widens and recontextualizes the theoretically developed instrument now to contest the idea of Citizen Science by adapting the "problem of extension" articulated by Collins and Evans [2002].

${ }^{2}$ The concept of Inclusion comprises forms of people involvement in a differentiated social sub-system [cf. Stichweh, 1988].

${ }^{3}$ In particular, those who are associated with risks and insecurities to a significant extent [Funtowicz and Ravetz, 1993] and those who could exert a negative impact on man and nature [Irwin, 1995].
} 
production of robust knowledge [e.g. Wynne, 1992]. The objectives related to the democratization of science [Kitcher, 2011], which find society-reflecting expression through concepts such as "post-normal science" [Funtowicz and Ravetz, 1993] or "mode 2" [Gibbons et al., 1994], entail and require more and more attention being paid to non-certified and non-professional understanding in the production of scientific knowledge to solve social problems. "The context speaks back" implies diagnosis and dictum at the same time [Nowotny, Scott and Gibbons, 2001]. Discussions held in the last few years reveal that the institutional demarcation line between scientists and citizens in the context of the participatory turn in scientific research and science policy is being put at stake [Jasanoff, 2003b], empirically challenged [Wynne, 1992] and analytically deconstructed [Collins and Evans, 2002].

However, the extension of the inclusion space to non-professional science raises an issue that has been clearly underscored by the sociologists Collins and Evans: the "problem of extension" [Collins and Evans, 2002, p. 235]. New institutions for civic participation, which are likely to enable the involvement of citizens in the decision-making process on a level playing field, according to Collins and Evans, solve the problem of the legitimization of scientific knowledge production - the "problem of legitimacy". At the same time, however, they raise the following resultant problem: "How much more inclusive should these new institutions be? Who should be included and who excluded? In our terms, this is the 'Problem of Extension" " [Collins and Evans, 2002, p. 275].

According to Collins and Evans, the "problem of extension" is a "pressing intellectual problem of the age" [Collins and Evans, 2002, p. 235], since it is related to confidence in expertise. Modern science itself is understood as an institution, which initially solved the problem of confidence in expertise in modern society. The call for greater participation - which is also an expression of the legitimacy crises of experts in the light of more and more complex scientific and technical challenges [Weingart, 2001; Collins and Evans, 2002], - leads to the recurrence of the problem: How can confidence in the certainty of knowledge be established and guaranteed, if the circle of experts is extended beyond the science system? To what extent can and should non-scientists be involved in science and technology policy issues? Where does inclusion stop, when it seems more and more unlikely that scientists have privileged access to the truth?

At present, Citizen Science ${ }^{4}$ deals with the efforts to bridge the institutional gap between science and the public, although it clearly goes beyond what Collins and Evans had in mind, namely the different forms of political participation. The "problem of extension" no longer relates only to contexts where science policy decisions are made, but also to the area of scientific practice: science production and reception. A major driving force is the digital shift, which also and especially applies to science. Therefore we uphold the thesis according to which the digital shift raises a "new problem of extension", the contours of which are currently emerging.

\footnotetext{
${ }^{4}$ For an earlier and alternative understanding of "Citizen Science" as socially more responsive and responsible science, cf. Irwin [1995]. The current dynamics of Citizen Science draws attention to the fact that - in the fields of biodiversity and environmental research — the different forms of lay participation have never entirely disappeared. Re-mobilization is one of the objectives of current Citizen Science [Roy et al., 2012]. Success stories include the network of Open Air Laboratories (OPAL) financially backed by the Imperial College London. It fulfils an umbrella function for Citizen Science-Projects in the U.K., organized by universities, museums and NGOs. So far, 750,000 volunteers have been involved in OPAL-Projects [Conrad and Hilchey, 2011].
} 
This paper begins with an overview of the current opening up processes with regard to knowledge production and reception (2), followed by our views brought together in a typology, which enables new, digitally-supported inclusion models to be placed in an analytical context. This in turn allows a more differentiated specification of the scope and the depth of the social opening up of science in the future (3). On the basis of our typology we will formulate our thesis, according to which - in the context of the digital shift - the demarcation line between certified experts (professional scientists) and lay people (non-scientists) is blurring (4).

The opening up of knowledge production and reception
To explain our thesis, we shall first outline Citizen Science as a new mode of knowledge production. Afterwards, we shall demonstrate that the digital shift not only supports new forms of knowledge production, but also enables new modes of knowledge reception via non-scientists.

Citizen Science transcends the epistemic authority of experts to the benefit of lay people. The concept of Citizen Science has been programmatically widened over the course of the last few years at national ${ }^{5}$ and international ${ }^{6}$ level [Roy et al., 2012; Suomela and Johns, 2012; Haklay, 2013]. Citizen Science today often refers to methods of science-driven Crowdsourcing. By the term 'crowdsourcing' we mean division of labour, where an actor (typically an organization) - by means of the digital media - delegates a given task to an anonymous crowd, who voluntarily perform the task. A task normally performed by members of the organization is outsourced [Howe, 2010; Estellés-Arolas and Guevara, 2012]. Crowdsourcing is possible thanks to new digital infrastructures, which can potentially reach anyone interested.

Forms of "Crowd science" [Franzoni and Sauermann, 2014] also entail delegating online data collection and assessment to the public. Widespread participation and diversified performance of the same task by different people is likely to ensure reliability even when the qualifications of project participants cannot be checked [Roy et al., 2012, p. 61]. "Crowd science" enables the implementation of large data-intensive projects, which could hardly be implemented by a limited number of employees [Franzoni and Sauermann, 2014, p. 17]. The core is a scientific project team that works within a scientific organization, in which experts identify problems, set the boundaries of the solution space and identify possible solutions. The general rule in this form of Citizen Science is that simple tasks are often delegated to non-certified actors, i.e. research work which needs to be carried out within pre-defined structures.

\footnotetext{
${ }^{5}$ Thanks to the newly-established digital platform buergerschaffenwissen.de the German Federal Ministry of Training and Research is currently financing a large joint project on Citizen Science. Research policy guidelines are set out according to public participation levels. About one third of German citizens - according to a survey - may participate in a Citizen Science project [Wissenschaft im Dialog (Science in Dialogue), 2014].

${ }^{6}$ On the establishment of the European Citizen Science Association (ECSA) in 2013, the EU-commissioner for research Janez Potoènik set out the objective to involve 5 million citizens as Citizen Scientists [Helmholtz Zentrum für Umweltforschung, 2014]. In line with the Digital Agenda of the European Commission, the participation of citizens in the research process by means of the digital media is considered of the utmost importance [Digital Science in Horizon 2020] and the EU-research programme "Horizon 2020" deals with the range of topics related to the significance of the civic society in science production. A 'Citizen Science Strategy 2020 for Europe' is currently being worked out.
} 
A core of the current Crowd science is the Internet platform Zooniverse, which is financially backed by several universities and can count on the participation of 1,333,054 Citizen Scientists, according to the information provided on the same platform (data refer to $27^{\text {th }}$ May 2015). Platform projects typically focus on data assessment carried out by the Crowd. The platform originates from the project Galaxy Zoo, which focuses on the classification of galaxies carried out by the "Crowd". At present, the platform Galaxy Zoo includes over 30 projects: astronomy is no longer the only project area; even biomedical cancer research is covered. Other project areas playing a major role include biodiversity and environmental monitoring, where mobile devices are used to identify animals and plants or to record noise and light pollution.

In the same way as with the Crowdsourcing approach to economics, Crowd science is associated with the hope to be able to count on an almost unlimited number of virtual staff, towards whom no formal obligations exist and where there are no temporal, spatial and financial limitations, as would normally apply to formal organisations [Kleemann, Voß and Rieder, 2008; Anderson, 2012, pp. 143foll.].

Apart from the Crowd science-related approaches discussed above, the concept of Citizen Science identifies forms of non-professional scientific practice, which have been marginalized in the context of academic professionalization but have not altogether disappeared - one may think, for instance, of the members of natural history societies or city historians [Finke and Laszlo, 2014]. ${ }^{7}$ The major changes brought about by digitization include the fact that digital communication facilitates links between amateur scientists, produces reciprocal visibility and enables the public representation of research beyond the circle of professional scientists to reach the public at large, through the creation and editing of Wikipedia articles. Finally, digitalization increases the means at the disposal of amateur scientists through the use and further development of open-source software and hardware [Haklay, 2013; Wylie et al., 2014; Xue, 2014]. ${ }^{8}$

Therefore, a number of authors forecast the opportunity to introduce a new "bottom-up" approach to science, which brings together marginalized practices of amateur research and current trends towards Open Science and Open Source. Paradigmatically, reference needs to be made to the "Biohacking" Scene, which has joined the above-mentioned trends to be able to practice life science also outside established institutional settings [Bennett et al., 2009; Delfanti, 2010; Wylie et al., 2014]. With regard to biohackers, Seyfried, Pei and Schmidt [2014] have come to the conclusion that prototypical forms of the opening up of science can be outlined, which are no longer focused on a safe experts/lay people difference [Seyfried, Pei and Schmidt, 2014].

\footnotetext{
${ }^{7}$ In this regard, Wylie et al. [2014] speak of "Citizen Science" to distinguish these forms of citizen science from the prevailing figuration of Citizen Science as Crowd Science. Similarly, Finke and Laszlo [2014] makes a distinction between "light" Citizen Science and "proper" Citizen Science. Whereas "light"“ Citizen Science promotes inclusion in existing institutions, "proper" Citizen Science supports countercultural practices, which put existing institutions at stake [McQuillan, 2014].

${ }^{8}$ Technically advanced opportunities for analysis and manipulation hardly ever existed in the $20^{\text {th }}$ century for amateur scientists. Most activities of amateur scientists focused on the humanities and on classical natural history areas, which mirrored the constraints existing at that time [cf. Finke and Laszlo, 2014].
} 
The opening up of knowledge production in Citizen Science finds complementarity in the new opportunities of scientific knowledge reception. With the shift from the press to digital information dissemination technologies and the drive towards Open Access, scholarly communication is currently going through a transition stage [Nentwich, 2003; Franzen, 2011, pp. 82foll.]. With regard to Open Access publications, scientific information can reach anyone interested, since institutional knowledge barriers have been broken down. At the same time - in the digital space - we change our reception habits and opportunities to assess scientific contributions increase.

Since the shift to electronic publishing, new online platforms have been developed where a published article is evaluated or where a draft article is discussed. Moreover, beyond the mass media special science blogs were established providing information about new scientific findings in (natural) science (e.g. Research Blogging), assessing them (e.g. PubPeer) or drawing attention to mistakes in publications (e.g. Retraction Watch). Wikipedia, collaborative plagiarism hunt and documentation like the German VroniPlag envisage open collaboration by anyone. With reference to the book sector, Amazon has become the largest literature criticism portal, even for specialized and professional books. Traditional expert roles in scientific specialized literature are joined by new forms of public (lay) commentaries [Nentwich and König, 2012; Kriegeskorte, 2012; Franzen, 2016, in press].

Apart from the numerous commentary options offered by online specialized publications, the reception behaviour towards scientific publications is increasingly registered and assessed by means of tracking systems. In addition to scientific quotes, other appeal factors include media reports and tweets, bookmarks or downloads of a given article [Lin and Fenner, 2013]. On the basis of what is known as Altmetrics [Priem, 2013] — an alternative to simple citations - software tools have been developed since 2009 to register and reveal the impact of a single contribution made by user-generated data in Web 2.0.

In this way, comments and reception habits of non-scientists can make an impact on science, namely first as scientific self-observation, which - so far and primarily has focused on the scientific appeal per se of citations in specialized publications. Web-based utilization statistics and other research outputs related to the different Altmetrics services include data, which — in principle — can be generated by anyone (even from bots). Science policy too sees an emerging trend towards a softening of the rigorous science-related inclusion rules, which is mirrored - inter alia - by the attention devoted to and the assessment of the "societal impact" in the framework of research assessment [Bornmann, 2012]. Research evaluation has been carried out by academic colleagues; recently — as is the case with the evaluation of higher education institutions in the U.K. - research users too are regularly involved in the assessment [cf. Manville et al., 2015]. In the context of the digital shift, the wider public of research communication is accompanied by a clear change of the different forms of scientific output as well as of the public itself. 
Extension of the inclusion space to non-certified expertise

The features outlined above foreshadow new opportunities for scientific participation in the context of the digital media, which is seen as the democratization of science by the EU Commission down to civil society activists. This normative interpretation is linked to a far-reaching, comprehensive debate on the democratizing features of the Internet in general and the Web 2.0 in particular [Dickel and Schrape, 2015]. In the present article, we shall question the idea of democratization with a sociological interpretation, which regards the opening up of knowledge production and reception as the extension of the inclusion space to non-certified scientific expertise. The inclusion space is subdivided into typologies as featured below.

We identify inclusion models with regard to expertise, ${ }^{9}$ which is attributed to the included actors. Following on from Collins and Evans [2007], we shall distinguish several levels of expertise, which — in descending order - are considered comparable to science:

- contributory expertise: Expertise corresponding to a scientist in a particular scientific area,

- interactional expertise: Expertise enabling technical communication with experts of a given scientific area as well as informed decisions,

- primary source knowledge: Expertise originating from the reception of scientific literature,

- beer-mat knowledge: Expertise requiring only schematic knowledge which fits on a beer mat. ${ }^{10}$

The decisive point - according to Collins and Evans - is that the level of expertise is not congruent with the effective inclusion in science. Science, in fact, primarily orientates itself to the certified membership of a professional science group. Non-certified expertise is institutionally excluded when it reaches the 'contributory' or 'interactional' levels.

The guiding principle upheld by Collins and Evans is that scientific and technical debates should involve those who can boast adequate expertise, irrespective of formal certifications. According to them, scientific and technical debates should not involve primarily "lay people" but non-certified experts who are considered (erroneously) lay people since they do not possess any formal qualifications. At the same time - according to a directive - we should limit participation requests and exclude "real" lay people - at least where the discussion is no longer about values and norms, but about scientific and technical decisions [Collins and Evans, 2002].

At this stage, mention should be made of the criticism drawn by the conceptualization of expertise by Collins and Evans. Critical reviews complain that the authors have fallen behind the premises of constructivism, perpetuate an

\footnotetext{
${ }^{9}$ Following on from Collins and Evans, what emerges is a general concept of expertise based on the well-versed participation in social practice. The concept differs from a specific concept of the expert, which refers to a particular social figure of experts as knowledge intermediaries and mediators in fully differentiated scientific communities [Stehr and Grundmann, 2010].

${ }^{10}$ We relinquish at this point finer differentiations in the field of specialized expertise [cf. Collins and Evans, 2007].
} 
inadequate understanding of participation (which might not end with the support for knowledge) as well as a simplistic reconstruction of prevalent studies on expertise [Pielke, 2007; Stehr and Grundmann, 2010, among others] and the participation of lay people, as described in detail by Jasanoff [2003b] and Wynne [2003]. Nevertheless, we keep on resorting to Collins and Evans's categories in the same way, since we ignore the issue of the ontological content of expertise. Collins and Evans are interested in expertise as an objective feature of actors; we, instead, use the above-mentioned categories for the attribution of the different kinds of expertise. Therefore, we are not interested in whether or not people without certification possess "real" expertise or whether their inclusion is desirable. We are much more interested to know in what way new inclusion modes open the doors of science to people who cannot claim any certified expertise.

With reference to the first dimension, namely science production, we identify two roles: amateur scientists (1) and science participants (2). As to the second dimension, namely science reception, two roles can be outlined: amateur critics (3) and research recipients (4) (cf. Figure 1).

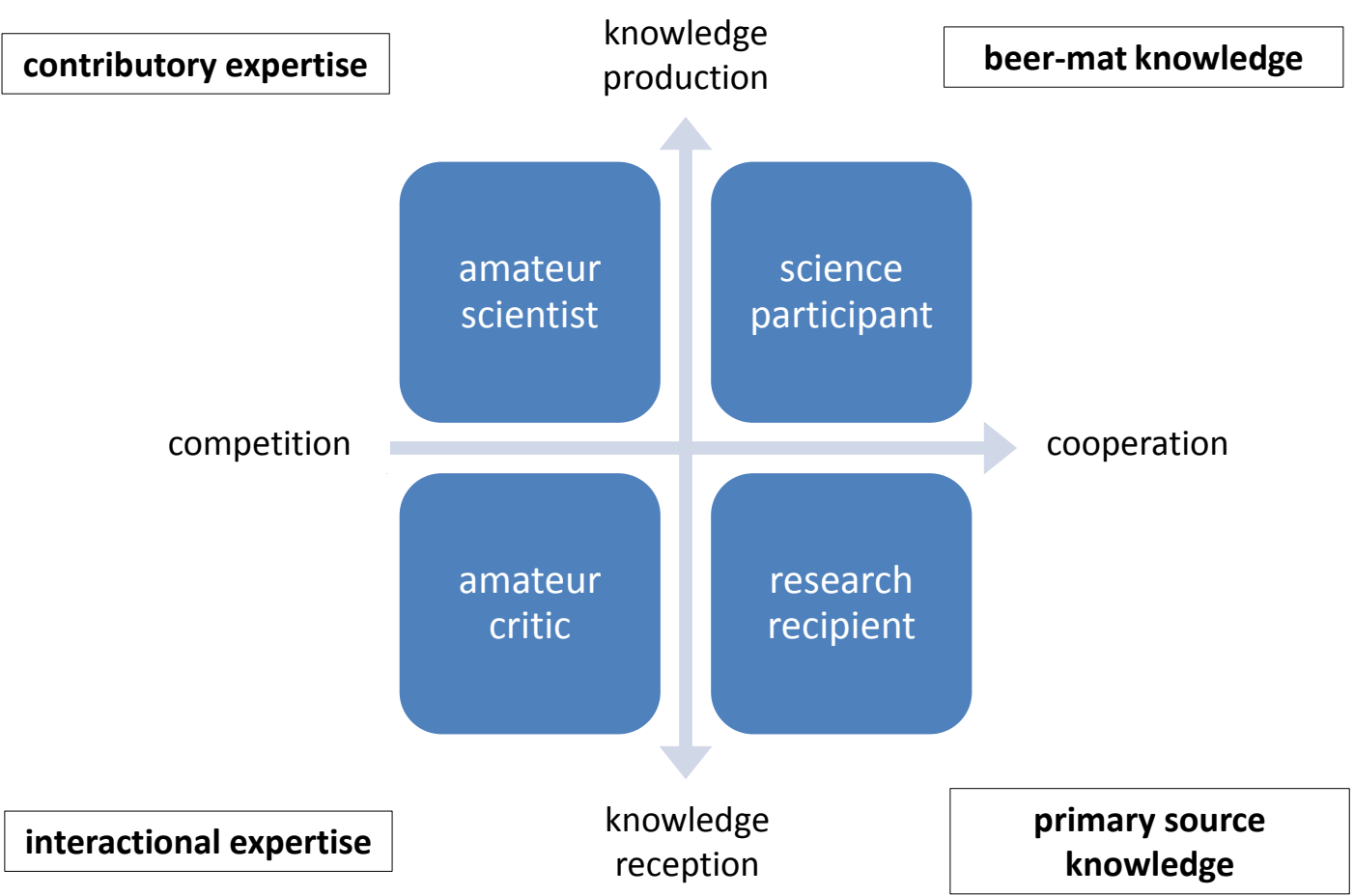

Figure 1. Inclusion space of non-certified expertise.

The above-mentioned roles are ideal types as defined by Max Weber; therefore they are not necessarily found in an empirically pure form. Our typologies serve - to a greater degree - as heuristics to draw attention to the prototypical manifestation of diversified inclusion efforts. On the one hand, inclusion efforts need to be differentiated below according to the expertise deemed necessary, socially attributed and/or demanded for a given inclusion form. On the other hand, they are typified to establish whether the link to certified expertise is characterized by competition or cooperation. In the former case, inclusion efforts on the part of professional scientists are expected to be rejected; in the latter case, instead, they tend to be fostered. 
The role set of professional scientists, who perform the roles of professional researcher, assistant, critic or recipient according to a given status or situation, acts as a blueprint of the typology developed here for the inclusion of lay people.

(1) The traditional figure of the amateur scientist has never altogether disappeared, indeed it is experiencing a renaissance with the emergence of Web 2.0. This particular case is about the inclusion of actors who claim contributory expertise. Competition between amateur science and professional science is usually implicit. It becomes explicit when successful publications of amateur scientists ${ }^{11}$ are pulled to pieces by the academic world ${ }^{12}$ or the other way round, when local historians or non-professional archaeologists deliberately withhold information and knowledge from scientific and specialist communities [Jung, 2010], or when biohackers style themselves as a more valuable alternative to commercialized molecular biology [Kelty, 2010; Delfanti, 2013; McQuillan, 2014]. Professional science is challenged here by actors who, on the grounds of self-ascribed expertise, confidently see themselves as an epistemic remedy for fossilized occupational science. ${ }^{13}$

(2) Whenever scientific debate focuses on Citizen Science, amateur scientists in the true sense of the word are normally excluded; included are rather forms of crowdsourcing where citizens are required to support professional scientists' work. Raising scientific issues, drawing up problem-solving strategies and interpreting final data are tasks that continue to be performed by professional scientists. Citizen's participation is often limited to data collection. The associated role is therefore defined as science participant. Science participants are not amateur scientists but they constitute forms of participation, which complement professional research. Scientific literacy is not a prerequisite for this auxiliary activity. Science has therefore access to types of performance, which do not necessarily envisage an analogy with scientific expertise; what suffices is beer-mat knowledge, which can be disseminated through web-based tutorials. However, the definition of science participant does not explain whether the actors involved mostly in crowd science projects are exploited by professional scientists or whether - conversely - the people involved can reap individual benefits from this auxiliary activity [Raddick et al., 2010]. ${ }^{14}$

(3) The role of amateur critics is unusual in modern science; it is a structurally competing role rather than a complementary one. ${ }^{15}$ With the creation of

\footnotetext{
11'Amateur' or 'non-professional' is a degrading definition, which - notoriously — is not only linked to the lack of a recognized professional status but also to the outcome of "Boundary Work" [Gieryn, 1983] to separate science from non-science.

${ }^{12}$ In historical scholarship, the problem clearly emerges in the struggle for interpretational sovereignty between academic historians and what are known as historians and publicists [Nolte, 2008].

${ }^{13}$ In contrast to classic amateur scientist figures like the gentleman scientist, new amateur scientists generally act collectively. People acting collectively do not have to surmount technological and structural hurdles posed by previous forms of collaborative research involving lay people [cf. Mahr, 2014].

${ }^{14}$ At this point, we must consider the ideal typical nature of the role set we have developed. Ideal types should be considered a framework within which a social practice can be developed. People who participate in crowdsourcing projects of environmental monitoring can therefore consider themselves amateur scientists to all effect. In the context of relevant projects, however, their role remains that of a contributor.

${ }^{15}$ Social and technological review infrastructures show how, as in the case of TripAdvisor in the tourism sector [Jeacle and Carter, 2011], the expression of opinions is no longer reserved to experts but can be extended to general users, enabling them to give their own views.
} 
relevant online platforms, ex-post evaluations have gained public dissemination. Amazon currently boasts the largest number of literary critics. ${ }^{16}$ Apart from the forms of cumulative assessment via the aggregation of single literary reviews, there are also electronic commentary functions in scientific journals, which can similarly be used by non-scientists for a critical review of scientific content. ${ }^{17}$ Moreover, there are collaborative undertakings like the documentation on plagiarism, which almost perform a scientific integrity monitoring function and therefore potentially integrate non-scientists in the assessment of performance and misperformance. What is required here are types of interactional expertise, featuring critics performing their role especially in the world of art [Collins and Evans, 2002, p. 244]. The inclusion of (amateur) critics is questioned whenever the assessment criteria that have been taken into account run counter to the internal attribution of scientific relevance.

(4) With regard to the fourth and last role - that of research recipients - the role is performed by online science recipients, who can therefore disrupt internal science reception and evaluation practices. With the shares, likes, downloads. re-tweets or views of science products in Web 2.0, user-generated data emerge, which - irrespective of the status of recipients and of their intentions - are included in the user statistics of scientific publishers or social (science) networks and increasingly become an alternative means to assess scientific performance [Franzen, 2015]. This anonymous public, to whom implicitly primary source knowledge is attributed - in so far as knowledge reception is concerned - is greatly valued by scientists, since it is increasingly important today to widen the scope of research activities. The preferences of people beyond the science system could become a component of performance. Along these lines, we attribute to research recipients as well as science participants the dimension of complementary participation, whereas amateur scientists and amateur critics compete with professional science (where non-certified expertise is required).

Our typology enables us to formulate an assumption, according to which complementary forms of knowledge production and reception only require little expertise. An equivalent level of expertise, which is necessary for amateur scientists and amateur critics to perform their roles raises - on the contrary — institutional friction. Whereas the relationship between professional scientists on the one hand and science participants and research recipients on the other hand is characterized by asymmetric cooperation, the relationship between amateur scientists and amateur critics on the one hand and professional scientists on the other hand is characterized

\footnotetext{
${ }^{16}$ All products traded on Amazon - from washing machines to scientific manuals — can be publicly reviewed by anyone. Irrespective of the content of the mostly anonymous reviews, the data related to numbered rating scale scores affect the visibility of products, for instance of specialist publications - controlled via an integrated technical support service which affects the reception behaviour of consumers as well as scientists, above all because it influences the visibility of publications.

${ }^{17}$ An empirical study of reader commentaries on scientific articles reveals that the asymmetry between scientists and non-scientists remains, despite new participation options: "[T]the conversations show little evidence of a more open expert-peer to expert-peer dialogue where scientific experts and personal experts can be peers. It shows us that achieving open dialogue between both types of experts in the public view requires more than just opportunity and a venue." [Shanahan, 2010, p. 10].
} 
by competition, since it implies or legally requires - as far as expertise is concerned - symmetrisation of professional and non-professional roles [cf. also Volkmann, 2010, pp. 216foll.].

The four inclusion profiles are ideal types that empirically encompass new forms of inclusion. The classification discloses that Citizen Science should be viewed in the broader context of the digital shift, which unfolds new social dynamics. Only then does it become manifest that Citizen Science opens up to lay people for both knowledge production and knowledge reception. Addressing and reaching people beyond the science system implies the informalization of scientific communication. Non-professional reviews are only featured in publications that are intelligible to all and deal with issues people encounter in everyday life. Crowd science is rather to be encountered in scientific areas, where large-scale data collection and/or data assessment appear meaningful. In the context of crowd science, participation in knowledge production neither requires any formal qualifications nor entails any interest in scientific issues or a compelling need to democratise expertise. On the contrary, the dissemination of 'bottom-up' amateur science in esoteric and labour-oriented areas appears less likely — or requires the elimination of technical access hurdles - as for instance the biohacker case illustrates. The main objective of biohackers is to acquire, share and empirically test life science knowledge outside established scientific institutions. Such types of amateur research can indeed be seen as the consistent realization of the central idea of a Citizen Science, which breaks down the social barriers of modern science [Delfanti, 2013]. When opportunity structures change with digitalization, it is necessary to monitor current and future adjustments of Citizen Science in an analytical way.

The new "Problem of Extension"
The extension of the inclusion space of science produces side effects, whose specification and investigation is likely to be facilitated by our typology. Whereas the "problem of extension" - according to Collins and Evans - was still based on deliberative participative contexts, what emerges now are new forms of knowledge co-construction, which include people irrespective of their professional affiliation to the system for knowledge production and reception. As a result, the question recently posed by Collins [2014] with regard to decisive science policy action, namely "Are we all scientific experts now?", ${ }^{18}$ appears to be increasingly relevant.

For now, we can answer the question in the negative. First, we want to clarify that the opening up of the science inclusion space does not affect the professional role of scientists. With reference to the role of scientists, a particular type of expertise is subordinate to institutional certification, testified by formal qualifications as well as the affiliation to a scientific institution. At present there are no signs foreshadowing the destabilization of the professional role. Moreover, our typology demonstrates that in the contexts where a greater inclusion complementary to one's professional role is in place and capable of adapting to the science system, science-related expertise is no longer a prerequisite for inclusion.

As our theoretical considerations suggest, the new "problem of extension" needs to be tackled bearing in mind that what loses relevance in an extended inclusion space

\footnotetext{
${ }^{18}$ The considerations of the thought leaders of Citizen Science tendentially suggest the above. With regard to Citizen Science, Finke and Laszlo [2014] shifts the distinction between science and non-science to the distinction between professional and non-professional/citizen science.
} 
with regard to professional and organizational criteria is the established distinction between certified and non-certified expertise for the science system as a knowledge production and reception context. For one thing, professional inclusion in the science system is no longer a prerequisite to be able to participate in science in the four above-mentioned modes. For another, the four modes are open in exactly the same way to professional scientists as well as to all other (digital) citizens: for example, when sociologists participate in the classification of galaxies or when mathematicians become plagiarism hunters for medicine PhDs. At any rate, the inclusion of actors in the science system is by no means universal or non-discriminating but highly selective. Knowledge production and knowledge reception are uncoupled, the scientific activity sector is split.

The inclusion profiles that have been studied are nevertheless of a prototypical nature. They do not reveal that - in the context of the digital shift - the transformation in scientific knowledge production is happening on a wide scale or that the role of scientists is de-professionalized. They reveal, though, that the digital shift opens up the relevant possibility spaces and that possibility spaces are already used selectively. How far-reaching the consequences of the digital shift will be is still uncertain; they need to be monitored and kept in check - our inclusion typology provides a heuristic instrument for that purpose.

Our considerations are already leading to a new theoretical formulation of the "problem of extension" in open science. In those contexts, where the distinction between certified and non-certified expertise loses structural relevance, the problem of confidence in expertise arises in a new form: the practices of institutional certification, which are essential for confidence in the epistemic authority of scientists, no longer affect the prototypical forms of inclusive science in a straightforward manner. Non-certified science-related expertise is required and attributed to areas characterized by sharp competition (amateur scientists and amateur critics). The quality of this type of expertise is not institutionally guaranteed [Bonney et al., 2014]. In the complementary forms of inclusive knowledge production and reception, science-related expertise is never a prerequisite, but this is exactly what raises the issue of the quality and the validity of generated data (in the case of input provided by the crowd/citizens) included in research projects as well as user-generated data that can be used as benchmarks (in the case of research recipients) to assess the impact of scientific works.

Apart from the "problem of extension" in the context of science policy considerations, what emerges is a similar "problem of extension". The main issue here is no longer what kind of "lay people" without formal certifications should be regarded as experts in the process of deliberation. On the contrary, the problem emerges in the core area of scientific practice. It is about the side effects of a dissolution of social boundaries in the societal knowledge production, which pushes into the background the institutional framework of scientific organizations, professional communities and the professional role of scientists itself.

Whether or not the social processing of the digital shift brings about social and technical mechanisms, which can tackle the problem in an appropriate way and increase confidence ${ }^{19}$ thanks to stable functional equivalents, is not only a

\footnotetext{
${ }^{19}$ In the field of data-driven research, the prevailing suggestion is that the "human element" as such becomes obsolete if data speak for themselves [Clark, 2013].
} 
controversial issue but also a starting point for future empirical research. To be able to ensure confidence in expertise also in the new digital constellations of knowledge acquisition, what seems indispensable is a new approach to epistemic authority.

Translated by Alexandra Speir

References

Anderson, C. (2012). Makers. The new industrial revolution. New York, U.S.A.: Crown Business.

Ben-David, J. (1991). Scientific Growth: Essays on the Social Organization and Ethos of Science. Ed. by G. Freundenthal. Berkeley, U.S.A.: University of California Press.

Bennett, G., Gilman, N., Stavrianakis, A. and Rabinow, P. (2009). ‘From synthetic biology to biohacking: are we prepared?' Nature Biotechnology 2712, pp. 1109-1111. DOI: 10.1038/nbt1209-1109.

Bonney, R., Shirk, J. L., Phillips, T. B., Wiggins, A., Ballard, H. L., Miller-Rushing, A. J. and Parrish, J. K. (2014). 'Next Steps for Citizen Science'. Science 343 (6178), pp. 1436-1437. DOI: 10.1126/science. 1251554.

Bornmann, L. (2012). 'Measuring the societal impact of research: research is less and less assessed on scientific impact alone - we should aim to quantify the increasingly important contributions of science to society'. EMBO reports 13 (8), pp. 673-676. DOI: 10.1038/embor. 2012.99.

Burzan, N., Lökenhoff, B., Schimank, U. and Schöneck, N. M. (2008). Das Publikum der Gesellschaft: Inklusionsverhältnisse und Inklusionsprofile in Deutschland. Springer-Verlag.

Clark, L. (2013). No questions asked: big data firm maps solutions without human input. Wired UK. URL: http://www. wired.co.uk/news/archive/2013-01/16/ayasdibig-data-launch (visited on 29th May 2015).

Collins, H. M. and Evans, R. (2002). 'The Third Wave of Science Studies. Studies of Expertise and Experience'. Social Studies of Science 32 (2), pp. 235-296. DOI: 10.1177/0306312702032002003.

- (2007). Rethinking expertise. Chicago, U.S.A. and London, U.K.: University of Chicago Press.

Collins, H. (2014). Are We All Scientific Experts Now? Cambridge, U.K.: Polity Press.

Conrad, C. C. and Hilchey, K. G. (2011). 'A review of citizen science and community-based environmental monitoring: issues and opportunities'. Environmental Monitoring and Assessment 176 (1), pp. 273-291. DOI: 10.1007/s10661-010-1582-5.

Delfanti, A. (2010). 'Users and peers. From citizen science to P2P science'. JCOM 9 (1), E. URL: http://jcom. sissa.it/archive/09/01/Jcom0901\%282010\%29E.

- (2013). Biohackers. The politics of open science. London, England: Pluto Pres.

Dickel, S. and Franzen, M. (2015). 'Digitale Inklusion. Zur sozialen Öffnung des Wissenschaftssystems'. Zeitschrift für Soziologie 44 (5), pp. 330-347. URL: http://www.zfs-online.org/index.php/zfs/article/view/3225.

Dickel, S. and Schrape, J.-F. (2015). 'Dezentralisierung, Demokratisierung, Emanzipation. Zur Architektur des digitalen Technikutopismus'. Leviathan 43 (3), pp. 442-463. DOI: 10.5771/0340-0425-2015-3-442.

Estellés-Arolas, E. and Guevara, F. González-Ladrón-de (2012). ‘Towards an integrated crowdsourcing definition'. Journal of Information Science 38 (2), pp. 189-200. DOI: 10.1177/0165551512437638. 
European Commission. Digital Science in Horizon 2020. URL: http: //ec . europa . eu /digital-agenda/en/news/digital-science-horizon-2020 (visited on 29th May 2015).

Finke, P. and Laszlo, E. (2014). Citizen Science: Das unterschätzte Wissen der Laien. oekom verlag.

Franzen, M. (2011). Breaking News. Wissenschaftliche Zeitschriften im Kampf um Aufmerksamkeit. Baden Baden, Deutschland: Nomos.

- (2015). ‘Der Impact Factor war gestern. Altmetrics und die Zukunft der Wissenschaft'. Themenheft: Der impact des impact factors. Soziale Welt 66 (2), pp. 225-242.

- (2016, in press). 'Science between Trust and Control: Non-Reproducibility in Scholarly Publishing'. In: Reproducibility: Principles, Problems, Practices and Prospects. Ed. by H. Atmanspacher and S. Maasen. New York, U.S.A.: Wiley, pp. 468-485.

Franzoni, C. and Sauermann, H. (2014). 'Crowd science: The organization of scientific research in open collaborative projects'. Research Policy 43 (1), pp. 1-20. DOI: $10.1016 / j$.respol .2013.07.005.

Funtowicz, S. O. and Ravetz, J. R. (1993). 'Science for the post-normal age'. Futures 25 (7), pp. 739-755. DOI: 10.1016/0016-3287 (93)90022-L.

Gibbons, M., Limoges, C., Nowotny, H., Schwartzman, S., Scott, P. and Trow, M. (1994). The New Production of Knowledge. The Dynamics of Science and Research in Contemporary Societies. London, England: Sage.

Gieryn, T. F. (1983). 'Boundary-Work and the Demarcation of Science from Non-Science: Strains and Interests in Professional Ideologies of Scientists'. American Sociological Review 48 (6), pp. 781-795. DOI: 10.2307/2095325.

Haklay, M. (2013). 'Citizen Science and Volunteered Geographic Information: Overview and Typology of Participation'. In: Crowdsourcing Geographic Knowledge. Ed. by D. Sui, S. Elwood and M. Goodchild. Dordrecht: Springer Netherlands, pp. 105-122. DOI: 10.1007/978-94-007-4587-2_7.

Helmholtz Zentrum für Umweltforschung (2014). Bürger schaffen Wissen. Wie Citizen Science in Deutschland ausgebaut werden soll. Pressemitteilung vom 07.07.2014. URL: http: //www . ufz.de/index.php?de=32981 (visited on 29th May 2015).

Howe, J. (2010). Crowdsourcing. Why the Power of the Crowd is Driving the Future of Business. URL: http: //crowdsourcing. typepad. com (visited on 29th May 2015).

Irwin, A. (1995). Citizen Science: A Study of People, Expertise and Sustainable Development. Psychology Press.

Jasanoff, S. (2003a). 'Breaking the Waves in Science Studies Comment on H.M. Collins and Robert Evans, 'The Third Wave of Science Studies". Social Studies of Science 33 (3), pp. 389-400. DOI: 10.1177/03063127030333004.

- (2003b). 'Technologies of Humility: Citizen Participation in Governing Science'. Minerva 41 (3), pp. 223-244. DOI: 10.1023/A : 1025557512320.

Jeacle, I. and Carter, C. (2011). 'In TripAdvisor we trust: rankings, calculative regimes and abstract systems'. Accounting, Organizations and Society 36 (4), pp. 293-309. DOI: 10.1016/j.aos. 2011.04.002.

Jung, M. (2010). "Heimathirsche": Hobbyarchäologen zwischen Hedonismus und Professionalisierung. Münster, Deutschland: Waxmann.

Kelty, C. M. (2010). 'Outlaw, hackers, victorian amateurs. Diagnosing public participation in the life sciences today'. JCOM 9 (1), C03. URL: http://jcom. sis sa.it/archive/09/01/Jcom0901\%282010\%29C01/Jcom0901\%282010\%29C03.

Kitcher, P. (2011). Science in a Democratic Society. Amherst, NY, U.S.A.: Prometheus Books. 
Kleemann, F., Voß, G. G. and Rieder, K. (2008). 'Crowdsourcing und der Arbeitende Konsument'. Arbeits- und Industriesoziologische Studien 1 (1), pp. 29-44.

Kriegeskorte, N. (2012). 'Open evaluation: a vision for entirely transparent post-publication peer review and rating for science'. Frontiers in Computational Neuroscience 6, p. 79. DOI: 10.3389/fncom. 2012.00079.

Lin, J. and Fenner, M. (2013). 'Altmetrics in Evolution: Defining and Redefining the Ontology of Article-Level Metrics'. ISQ 25 (2), pp. 20-26.

Mahr, D. (2014). Citizen Science: partizipative Wissenschaft im späten 19. und frühen 20. Jahrhundert. Baden-Baden, Deutschland: Nomos.

Manville, C., Guthrie, S., Henham, M.-L., Garrod, B., Sousa, S., Kirtley, A., Castle-Clarke, S. and Ling, T. (2015). Assessing impact submissions for REF2014: an evaluation. RR-1032-HEFCE.

McQuillan, D. (2014). 'The Countercultural Potential of Citizen Science'. Journal of Media and Culture 17 (6). URL: http://journal.media-culture.org.au/index .php/mcjournal/article/view/919.

Nentwich, M. (2003). Cyberscience: research in the age of the Internet. Vienna, Austria: Austrian Academy of Sciences Press.

Nentwich, M. and König, R. (2012). Cyberscience 2.0. Research in the age of digital social networks. Frankfurt, Deutschland: Campus.

Nolte, P. (2008). Öffentliche Geschichte. Die neue Nähe von Fachwissenschaft, Massenmedien und Publikum: Ursachen, Chancen, Grenzen. Ed. by M. Barricelli and J. Hornig. Frankfurt am Main [u.a.]: Lang, pp. 131-146.

Nowotny, H., Scott, P. and Gibbons, M. (2001). Re-Thinking Science. Knowledge and the Public in an Age of Uncertainty. Cambridge, England: Cambridge University Press.

Pielke, R. A. J. (2007). The Honest Broker. Cambridge, U.S.A.: Cambridge University Press.

Priem, J. (2013). 'Scholarship: Beyond the paper'. Nature 495 (7442), pp. 437-440. DOI: $10.1038 / 495437$ a.

Raddick, M. J., Bracey, G., Gay, P. L., Lintott, C. J., Murray, P., Schawinski, K., Szalay, A. S. and Vandenberg, J. (2010). 'Galaxy Zoo. Exploring the Motivations of Citizen Science Volunteers'. Astronomy Education Revie 9 (1). DOI: 10.3847/AER2009036.

Roy, H. E., Pocock, M. J. O., Preston, C. D., Roy, D. B., Savage, J., Tweddle, J. C. and Robinson, L. D. (2012). Understanding citizen science and environmental monitoring: final report on behalf of UK Environmental Observation Framework. URL: http://www . ukeof .org.uk/documents/understanding-citizen-science.pdf.

Schimank, U. (2012). 'Wissenschaft als gesellschaftliches Teilsystem'. In: Handbuch Wissenschaftssoziologie. Ed. by S. Maasen, M. Kaiser, M. Reinhart and B. Sutter. Springer Fachmedien Wiesbaden, pp. 113-123. DOI: 10.1007/978-3-531-18918-5_9.

Seyfried, G., Pei, L. and Schmidt, M. (2014). ‘European do-it-yourself (DIY) biology: Beyond the hope, hype and horror'. BioEssays 36 (6), pp. 548-551. DOI: 10.1002/bies. 201300149.

Shanahan, M.-C. (2010). 'Changing the meaning of peer-to-peer? Exploring online comment spaces as sites of negotiated expertise'. JCOM 9 (1), A01. URL: http://jcom.sissa.it/archive/09/01/Jcom0901\%282010\%29A01.

Stehr, N. and Grundmann, R. (2010). Expertenwissen: Die Kultur und die Macht von Experten, Beratern und Ratgebern. Weiland, Deutschland: Velbrück. 
Stichweh, R. (1988). 'Inklusion in Funktionssysteme der modernen Gesellschaft'. In: Differenzierung und Verselbständigung. Zur Entwicklung gesellschaftlicher Teilsysteme. Ed. by R. Mayntz, B. Rosewitz and U. Schimank. Frankfurt a.M., Deutschland: Campus Verlag GmbH, pp. 261-293.

Suomela, T. and Johns, E. (2012). 'Citizen Participation in the Biological Sciences: A Literature Review of Citizen Science'. Annual Research Symposium of the College of Communication and Information. URL:

http://trace.tennessee.edu/ccisymposium/2012/poster/8 (visited on 29th May 2015).

Volkmann, U. (2010). 'Sekundäre Leistungsrolle. Eine differenzierungstheoretische Einordnung des Prosumenten am Beispiel des „Leser-Reporters"”. In: Prosumer Revisited. Zur Aktualität einer Debatte. Ed. by B. Blättel-Mink and

K.-U. Hellmann. Wiesbaden, Deutschland: VS Verlag für Sozialwissenschaften, pp. 206-220. DOI: 10.1007/978-3-531-91998-0_11.

Weingart, P. (2001). Die Stunde der Wahrheit? Weilerswist, Deutschland: Velbrück Wissenschaft.

Wissenschaft im Dialog (Science in Dialogue) (2014). Wissenschaftsbarometer 2014. URL: http://www . wissenschaft-im-dialog.de/fileadmin/user_upload/Proj ekte/Wissenschaftsbarometer/Dokumente/Ergebnistabellen_Wissbarometer 2014_neu.pdf (visited on 29th May 2015).

Wylie, S. A., Jalbert, K., Dosemagen, S. and Ratto, M. (2014). 'Institutions for Civic Technoscience: How Critical Making is Transforming Environmental Research'. The Information Society 30 (2), pp. 116-126. DOI: 10.1080/01972243.2014.875783.

Wynne, B. (1992). 'Misunderstood misunderstanding: social identities and public uptake of science'. Public Understanding of Science 1 (3), pp. 281-304. DOI: 10.1088/0963-6625/1/3/004.

- (2003). 'Seasick on the Third Wave? Subverting the Hegemony of Propositionalism: Response to Collins \& Evans (2002)'. Social Studies of Science 33 (3), pp. 401-417. URL: http://www . jstor.org/stable/3183124.

Xue, K. (2014). 'Popular Science. In the Internet era, research moves from professionals' labs to amateurs' homes'. Harvard Magazine (January-February 2014). URL: http://harvardmagazine.com/2014/01/popular-science.

Authors

Sascha Dickel is a senior researcher at the Friedrich Schiedel Endowed Chair for Sociology of Science at TU München. He holds a PhD in sociology from Bielefeld University. His main research topics are social theory, digitalization, citizen science and foresight. E-mail: sascha.dickel@tum.de.

Martina Franzen, holds a PhD in sociology from Bielefeld University. She is a senior researcher at the WZB Berlin Social Science Center in the Research Group Science Policy Studies. Her research focuses on social theory, open science, science and the media studies and scholarly communication in the digital age.

E-mail: martina.franzen@wzb.eu.

How to cite
Dickel, S. and Franzen, M. (2016). 'The "Problem of Extension" revisited: new modes of digital participation in science'. JCOM 15(01), A06_en.

This article is licensed under the terms of the Creative Commons Attribution - NonCommercial NoDerivativeWorks 4.0 License.

ISSN 1824 - 2049. Published by SISSA Medialab. http://jcom.sissa.it/. 